University of Nebraska - Lincoln

DigitalCommons@University of Nebraska - Lincoln

Publications, Agencies and Staff of the U.S.

Department of Commerce

U.S. Department of Commerce

2000

Incorporating Uncertainty into Management Models for Marine Mammals

\author{
Barbara L. Taylor \\ Southwest Fisheries Science Center, taylor@caliban.ucsd.edu \\ Paul R. Wade \\ National Marine Fisheries Service \\ Douglas P. De Master \\ National Marine Mammal Laboratory \\ Jay Barlow \\ Southwest Fisheries Science Center, jay.barlow@noaa.gov
}

Follow this and additional works at: https://digitalcommons.unl.edu/usdeptcommercepub

Part of the Environmental Sciences Commons

Taylor, Barbara L.; Wade, Paul R.; De Master, Douglas P.; and Barlow, Jay, "Incorporating Uncertainty into Management Models for Marine Mammals" (2000). Publications, Agencies and Staff of the U.S.

Department of Commerce. 233.

https://digitalcommons.unl.edu/usdeptcommercepub/233

This Article is brought to you for free and open access by the U.S. Department of Commerce at DigitalCommons@University of Nebraska - Lincoln. It has been accepted for inclusion in Publications, Agencies and Staff of the U.S. Department of Commerce by an authorized administrator of DigitalCommons@University of Nebraska - Lincoln. 


\title{
Incorporating Uncertainty into Management Models for Marine Mammals
}

\author{
BARBARA L. TAYLOR, ${ }^{*} \mathbb{8}$ PAUL R. WADE, $†$ DOUGLAS P. DE MASTER, $\neq$ \\ AND JAY BARLOW* \\ *Southwest Fisheries Science Center, 8604 La Jolla Shores Drive, La Jolla, CA 93028, U.S.A. \\ †Office of Protected Resources, National Marine Fisheries Service, c/o National Marine Mammal Laboratory, \\ 7600 Sand Point Way N.E., Building 4, Seattle, WA 55108, U.S.A. \\ $\ddagger$ National Marine Mammal Laboratory, 7600 Sand Point Way N.E., Building 4, Seattle, WA 55108, U.S.A.
}

\begin{abstract}
Good management models and good models for understanding biology differ in basic philosophy. Management models must facilitate management decisions despite large amounts of uncertainty about the managed populations. Such models must be based on parameters that can be estimated readily, must explicitly account for uncertainty, and should be simple to understand and implement. In contrast, biological models are designed to elucidate the workings of biology and should not be constrained by management concerns. We illustrate the need to incorporate uncertainty in management models by reviewing the inadequacy of using standard biological models to manage marine mammals in the United States. Past management was based on a simple model that, although it may bave represented population dynamics adequately, failed as a management tool because the parameter that triggered management action was extremely difficult to estimate for the majority of populations. Uncertainty in parameter estimation resulted in few conservation actions. We describe a recently adopted management scheme that incorporates uncertainty and its resulting implementation. The approach used in this simple management scheme, which was tested by using simulation models, incorporates uncertainty and mandates monitoring abundance and buman-caused mortality. Altbough the entire scheme may be suitable for application to some terrestrial and marine problems, two features are broadly applicable: the incorporation of uncertainty through simulations of management and the use of quantitative management criteria to translate verbal objectives into levels of acceptable risk.
\end{abstract}

Incorporación de la Incertidumbre en Modelos de Manejo para Mamíferos Marinos

Resumen: Los modelos buenos de manejo y los modelos buenos para el conocimiento de la biología difieren en su filosofía básica. Los modelos de manejo pueden facilitar las decisiones de manejo a pesar de la gran cantidad de incertidumbre sobre las poblaciones manejadas. Estos modelos pueden estar basados en parámetros que pueden ser fácilmente estimados, la mayoría considera explícitamente la incertidumbre $y$ deberían ser simples de entender e implementar. En contraste, los modelos biológicos son diseñados para elucidar el funcionamiento de la biología y no son restringidos por asuntos de manejo. En este trabajo ejemplificamos la necesidad de incorporar la incertidumbre en los modelos de manejo mediante la revisión de la incompetencia en el uso de modelos biológicos convencionales en el manejo de mamíferos marinos en los Estados Unidos. En el pasado el manejo se basaba en un modelo simple que a pesar de poder representar las dinámicas poblacionales adecuadamente, fallaba como una berramienta de manejo debido a que el parámetro que desencadenaba las acciones de manejo era extremadamente difícil de estimar para la mayoría de las poblaciones. La incertidumbre en la estimación de parámetros resultó en pocas acciones de conservación. Describimos un esquema de manejo recientemente adoptado que incorpora la incertidumbre y su implementación resultante. La metodología usada en este esquema simple de manejo, el cual ha sido probado usando modelos de simulación, incorpora la incertidumbre y determina el monitoreo de la abundancia y la mortalidad causada por humanos. A pesar de que el esquema completo puede ser adecuado para aplicarse a problemas tanto terrestres como marinos, pocas características son ampliamente aplicables: la in-

\email taylor@caliban.ucsd.edu

Paper submitted September 2, 1999; revised manuscript accepted April 5, 2000. 
corporación de la incertidumbre mediante simulaciones de manejo y el uso de criterios cuantitativos de manejo para traducir objetivos verbales en niveles aceptables de riesgo.

\section{Introduction}

The primary goal of a management model is to use data to make decisions that result in meeting management objectives. Management objectives are usually defined by law, regulation, or some management body such as a fisheries council or a recovery team. For example, the primary objective of the U.S. Marine Mammal Protection Act (1972) is to maintain populations above a certain level. Yet after more than 20 years of management under this act, and despite declines in the abundance of some populations, only a few populations received any conservation action. The history of management using a biological model demonstrates that ignoring uncertainty results in failure to take needed conservation actions. We contrast this history with the current management model, proscribed in the 1994 amendment to the act, which explicitly incorporates uncertainty to rectify past inadequacies. The marine mammal example shows how a rarely implemented law can be turned into a functioning and proactive law through appropriate consideration of uncertainty. Another important feature of the new management scheme is that, prior to being written into law and regulations, it was tested by simulation of the management process. Our purpose is not to provide the details of the actual model and testing procedure, which have been published elsewhere (Taylor 1993; Wade 1998), but to provide the history of the development of a management model and emphasize that the new management scheme functions well largely because of the explicit treatment of uncertainty.

Management has failed in the past not because the model driving management actions did not adequately represent population dynamics but rather because the law was interpreted to require proof that populations were in a certain state ("depleted") before actions were taken. At an international level, at least part of the blame for the spectacular overexploitation of the great whales can be placed on scientists being unable to agree on parameters used in simple models to drive management decisions: there was no clear way to treat uncertainty. For brevity, we detail the evolution of management models for marine mammals within the United States, but a similar evolution has taken place in models developed by the International Whaling Commission (Cooke 1994). We then describe the current management model and how it differs in basic philosophy from models that scientists typically use to understand biological processes.

\section{The 1972-1993 Model for Marine Mammal Management in the United States}

The Marine Mammal Protection Act (MMPA) contains two primary objectives: to maintain populations (1) above their optimum sustainable population level (OSP) and (2) as functioning elements of their ecosystem. The first objective was defined by the National Marine Fisheries Service (NMFS; Gehringer 1976) as a population with abundance exceeding the maximum net productivity level (MNPL). The MNPL was defined as the population size that would yield ". . . the greatest net annual increment in population numbers or biomass resulting from additions to the population due to reproduction and/or growth less losses due to natural mortality." In theory, management action was essentially binary: no kills of marine mammals were allowed if population abundances fell below MNPL-formally classified as "depleted" under the MMPA-and no management actions were required for populations above MNPL. The problem was in estimating both what MNPL was and where the population was in relation to MNPL.

The concept of MNPL follows from the generally agreed principle that marine mammal populations experience density-dependent population growth. For example, a commonly used simple model (Pella \& Tomlinson 1969; Gilpin et al. 1976) that represents density-dependent growth is

$$
N_{t+1}=N_{t}+R_{\mathrm{MAX}} N_{t}\left(1-\left(\frac{N_{t}}{K}\right)^{\theta}\right),
$$

where $N$ is abundance, $t$ is time, $R_{\mathrm{MAX}}$ is maximum population growth rate, $K$ is carrying capacity, and $\theta$ is the shape parameter. The MNPL is determined by $K$ and $\theta$. If $\theta=1$, then equation 1 is a standard logistic equation with a linear decrease in growth between $N=0$ and $N=$ $K$, and MNPL $=0.5 K$.

Numerous theoretical papers have attempted to quantify MNPL as a proportion of carrying capacity for long-lived mammals (Goodman 1981; Fowler 1984; Fowler 1988; Gerrodette \& DeMaster 1990; Taylor \& DeMaster 1993). For example, Taylor and DeMaster (1993) examined combinations of density-dependent changes in age-specific birth and death rates and found it likely that MNPL is between $50 \%$ and $85 \%$ of carrying capacity.

\section{Results of 1972-1993 Management Model}

Of the 153 stocks (62 species) of marine mammals under U.S. management, assessments that in some way at- 
Table 1. Marine mammal stocks for which an attempt was made by the National Marine Fisheries Service to assess status relative to the maximum net productivity level (MNPL) prior to 1994 .

\begin{tabular}{|c|c|c|c|c|}
\hline Stocks ${ }^{a}$ & $\begin{array}{l}\text { Number } \\
\text { of stocks }\end{array}$ & Metbod $^{b}$ & Status ${ }^{c}$ & Source \\
\hline $\begin{array}{l}\text { Eastern tropical Pacific dolphins } \\
\quad \text { (spotted, spinner, common, striped) }\end{array}$ & 9 & back-calculation & $\mathrm{D}(2)$ & $\begin{array}{l}\text { Smith 1979, 1983; Wade } \\
\text { 1993a, 1993b, } 1994\end{array}$ \\
\hline Gray whale & 1 & $\begin{array}{l}\text { back-calculation, } \\
\text { dynamic response }\end{array}$ & no & $\begin{array}{l}\text { Reilly 1981; Gerrodette } \\
\text { \& DeMaster } 1990\end{array}$ \\
\hline Bowhead whale & 1 & back-calculation & $\mathrm{E}$ & Breiwick et al. 1981 \\
\hline $\begin{array}{l}\text { North Pacific small cetaceans } \\
\text { (Pacific white-sided dolphin, } \\
\text { northern right whale dolphin) }\end{array}$ & 2 & back-calculation & no & Hobbs \& Jones 1993 \\
\hline Harbor porpoise (California) & 1 & back-calculation & no & Barlow \& Hanan 1995 \\
\hline California pinnipeds (northern & & & & \\
\hline $\begin{array}{l}\text { elephant seal, California sea lion, } \\
\text { harbor seal) }\end{array}$ & 3 & dynamic response & no & $\begin{array}{l}\text { Boveng 1988a, 1988b, 1988c; } \\
\text { Boveng et al. } 1988\end{array}$ \\
\hline Steller sea lion & 2 & decline $>50 \%$ & E, $\mathrm{T}$ & Merrick et al. 1987 \\
\hline Northern fur seal & 1 & decline $>50 \%$ & $\mathrm{D}$ & York 1987 \\
\hline Bottlenose dolphin (Atlantic coast) & 1 & strandings & $\mathrm{D}$ & Scott et al. 1988 \\
\hline Total & 21 & & & \\
\hline
\end{tabular}

${ }^{a}$ Stocks on this list had a documented analysis (source) that attempted to determine population status relative to MNPL. Not all assessments had conclusive results. Scientific names not previously mentioned in the text: spotted dolphin (Stenella attenuata), common dolphin (Delphinus delphis), striped dolphin (Stenella coeruleoalba), bowhead whale (Balaena mysticetus), Pacific white-sided dolphin (Lagenorhynchus obliquidens), Northern elephant seal (Mirounga angustirostris), California sea lion (Zalophus californianus), harbor seal (Phoca vitulina), bottlenose dolphin (Tursiops truncatus).

${ }^{b}$ Back-calculation, calculating pre-exploitation size from estimates of recent abundance and annual estimates of buman-caused mortality; dynamic response, analysis of observed dynamics (Goodman 1988); decline $>50 \%$ observed trend indicating a decline in abundance of greater than 50\%; strandings, analysis of an anomalous stranding event.

${ }^{c}$ Status is $D$ for stocks designated as depleted under the Marine Mammal Protection Act (MMPA); $E$ or T for stocks listed as endangered or threatened under the ESA (and thus automatically considered depleted under the MMPA); or no for stocks not listed under the MMPA or ESA.

tempted to determine status relative to OSP were completed for 21 stocks over 21 years (Table 1). In U.S. waters (i.e., excluding eastern tropical Pacific dolphins), only $8 \%$ (12 of 153 ) of the stocks were assessed. We equate the definition of stock with management unit, which is essentially a unit-usually geographically delineated-defined to meet specified management objectives (for further discussion, see Moritz 1994; Taylor 1997). Attempts to directly estimate MNPL were made for only two species: spinner dolphins (Stenella longirostris; Smith 1984) and northern fur seals (Callorbinus ursinus; Ragen 1990). Ragen (1990) emphasized that MNPL could not be estimated reliably even for the largest available data set (northern fur seals). Reilly (1992) made the same point for California gray whales (Eschrichtius robustus), which are the best-known population of baleen whales. Attempts to estimate population level relative to MNPL (without actually estimating MNPL itself) were made for 17 stocks (Table 1), but few of these stock assessments were successful in unambiguously determining whether the stock was depleted. In addition, indirect methods, such as observed declines in abundance of over $50 \%$ were used to define three stocks as depleted without need for further consideration of population level relative to MNPL (Table 1). Only four stocks are currently designated depleted without also being listed under the U.S. Endangered Species Act, and only six other stocks (excluding eastern tropical Pacific dolphins) were for- mally assessed to see whether management actions were needed. We review two case studies to illustrate the management lessons learned during this period.

\section{Eastern Tropical Pacific Dolphins}

The case of tropical dolphins killed by tuna fishing illustrates the amount of data required before populations could be listed as depleted. In 1969 the first reports of high mortality of dolphins in the eastern tropical Pacific tuna purse-seine fishery (Perrin 1969) triggered a program to estimate total mortality (Lo \& Smith 1986). Increased observer coverage in the early 1970 s confirmed that mortality was high, which prompted dolphin abundance estimation surveys beginning in 1977. Several of the dolphin populations were estimated to be below MNPL (Smith 1983) based on abundance estimates (Holt \& Powers 1982), mortality estimates for 1959-1979, and assumptions about likely population growth rates. Disputes, including litigation from the tuna industry, about the uncertainty of several of the inputs into those analyses led an administrative law judge to reject such depletion designations (Marine Mammal Commission 1982). Conclusive analyses sufficient to justify the depleted status of these populations (Wade 1993a, 1993b) required a tremendous amount of data: nine abundance surveys over 12 years, 17 years of relative trend indices from data collected on the tuna vessels, 25 years of observer 
data on dolphin mortality rates in the fishery, and 34 years of data on fishing effort. The requirement to show conclusive proof led to a listing delay of 14 years from the first abundance survey and an estimated 23-year delay from the date of depletion (Wade 1994).

International management and industry actions in the early 1990s (Joseph 1994) led to a dramatic decline in the levels of dolphin mortality. These management actions were not clearly related to designation of the stocks as depleted under the MMPA.

\section{Harbor Porpoise in California}

In the mid-1980s, increasing numbers of stranded harbor porpoise (Pbocoena pbocoena), along with an expanding coastal gillnet fishery in central California, indicated that the population of harbor porpoise in the region of the fishery may have been at some risk. A fishery observer scheme was instituted to estimate the number of animals being killed, and surveys were conducted to estimate abundance. In an attempt to determine whether the population was depleted, the abundance of porpoise in earlier years was back-calculated using data on fishing effort and kill rates (Barlow \& Hanan 1995). Uncertainty in many parameters made determination of status relative to MNPL impossible. Nevertheless, approximately $10 \%$ of the population was being killed annually, and porpoise populations cannot grow fast enough to replace such large annual losses (Barlow \& Boveng 1991), so it was unlikely that the fishing mortality could be sustained by the local population. A larger population exists in northern California, but the extent of mixing between the local central California population and this northern California population was and is unknown. The potential problem of excessive kills was solved for the harbor porpoise not by MMPA actions but rather by actions under the Endangered Species Act to protect sea otters (Enbydra lutris) being killed in the same fishery, which closed so many areas that fishing became largely unprofitable. Again, the well-intentioned but unworkable former MMPA management scheme failed to protect its intended target.

\section{Lessons from the 1972-1993 Experience}

Although some management actions were taken during the MMPA's first 20 years, few were triggered by the mathematical model that defined depletion. Actions that were taken involved highly publicized issues such as the tuna-dolphin problem, in which hundreds of thousands of animals were taken in a concentrated fishery. Management actions resulted primarily from political pressure associated with problems that could be observed readily. Most fisheries had no monitoring of marine mammal mortality, and there were no abundance estimates for the vast majority of species. For species other than the few with a long time series of both kills and abundance (northern fur seals, eastern tropical Pacific dolphins, and gray whales), estimation of current status relative to historical numbers proved an impossible task. We also learned that using trends in abundance was a risky strategy for most cetacean species for which estimates of abundance are imprecise. Taylor and Gerrodette (1993) noted in reference to the vaquita (Pbocoena sinus), an endangered porpoise, that the species is likely to go extinct before a statistically significant trend can be determined.

We have learned that we can estimate three things fairly well: abundance, its associated precision, and mortality rates. Because many marine mammal populations are recovering from overexploitation, we also have numerous estimates of population growth rates that are probably close to the maximal rates. What was needed, then, was a management system that (1) was based on a model that used data we could gather, (2) incorporated uncertainties in the data, and (3) facilitated management decisions in a timely manner. In other words, we sought a management system that could be implemented and that could survive legal scrutiny. Further, a system was needed that could be easily explained to constituents in the environmental and fishery communities as well as to politicians and administrators who cannot be expected to be well versed in population dynamics.

\section{The Current Model for Marine Mammal Management}

Recognizing that the previous management regime was not working, in 1998 the U.S. Congress placed a moratorium on most MMPA provisions that dealt with fishery mortality and asked scientists at the NMFS and U.S. Fish and Wildlife Service to propose a new management scheme. The Marine Mammal Commission (Robert Hofman, testimony to Senate Committee on Commerce, Science and Transportation, 14 July 1993) defined the following objectives for marine mammal management: (1) maintain the fullest possible range of management options for future generations, (2) restore depleted species and populations of marine mammals to optimum sustainable level with no significant time delays, (3) reduce takes (kills) to as near zero as practicable, and (4) as possible, minimize hardships to commercial fisheries while achieving the previous objectives. These objectives are based on the precautionary principle of Holt and Talbot (1978): "Management decisions should include a safety factor to allow for the facts that knowledge is limited and institutions are imperfect," and "The magnitude of the safety factor should be proportional to the magnitude of risk." 
The new management regime grew out of proposals from the NMFS, the Marine Mammal Commission, fishing groups, and environmental organizations. It sought to do three things: (1) to explicitly consider uncertainty in management, (2) to base management on parameters that could be estimated, and (3) to provide incentives to gather better data. This regime, now part of the 1994 amendments to the MMPA, requires that total annual human-caused mortality and serious injury be less than potential biological removal (PBR), as follows:

$$
P B R=N_{\mathrm{MIN}} \frac{1}{2} R_{\mathrm{MAX}} F_{R},
$$

where, $N_{\mathrm{MIN}}$ is minimum population estimate, $R_{\mathrm{MAX}}$ is maximum population growth rate, and $F_{R}$ is recovery factor.

Behind the model is a simple idea: humans should not remove more than the population needs to maintain at least half of its current carrying capacity $(K)$ (or, if $K$ has been constant, historical numbers). To get an intuitive grasp of the PBR management scheme, consider an analogy of shooting at a target. Instead of a bullseye, the target is a square with a horizontal line bisecting the midpoint. For any given shot at the target, the goal is always (i.e., with high probability) to place your round above the line. This symbolizes maintaining populations above MNPL. Imagine that you want to make certain when you shoot that you hit above a line 95\% of the time. Now consider two guns: a pilgrim's musket and a sniper's rifle. The rifle shoots with great precision and is equivalent to an abundance estimate with a very low coefficient of variation (CV). Even an expert marksman, however, would be considerably less precise with the musket: repeated attempts with the musket result in a more diffuse pattern than with the rifle. To ensure a high probability of hitting the target above the line, the marksman would deliberately aim the musket higher than the rifle.

Using $N_{\mathrm{MIN}}$ in the PBR equation effectively raises the aiming point to adjust for poorer precision in the abundance estimates. The amount above the line the marksman needs to aim depends on the number of shots below the line deemed acceptable. In management terms, how often can we fail to meet the management objectives and still consider the result acceptable? This is where the balance is struck between contradicting goals, such as keep populations at safe levels while minimizing hardship to fisheries. The translation between policy and science is achieved by defining specific quantitative objectives called performance criteria, so called because they are the performance standard for the model. This not only allows uncertainty to be incorporated but sets the management scheme in an explicit framework of acceptable levels of risk. Thus, parties that assert that the scheme is over- or underprotective must argue for different levels of acceptable risk rather than about the details of the science. Uncertainty can no longer be used as a reason for inaction.
Three performance criteria were used for this management scheme: (1) populations recovering from depletion (taken to be $30 \% K$ ) will have a $95 \%$ probability of being above MNPL in 100 years; (2) healthy populations ( $\geq$ MNPL) will have a $95 \%$ probability of remaining above MNPL after 20 years; and (3) populations at high risk (taken to be $5 \% K$ ) will have a $95 \%$ probability of not delaying the time to reach MNPL by $>10 \%$ over a zero humancaused kill scenario. All these criteria, like a population viability analysis, frame performance in terms of a certain probability of an event occurring in a given amount of time.

The performance criteria define for the marksman (modeler) how often shots must be placed above the line. This is accomplished in two steps by tuning the model to achieve the desired performance. The first step treats uncertainty related to imprecision in the abundance data. Consider the performance of criterion \#1 that requires populations depleted to $30 \%$ of $K$ to reach MNPL in 100 years. Simulations start with the initial population at $30 \%$ of $K$ and "manage" the populations by simulating abundance

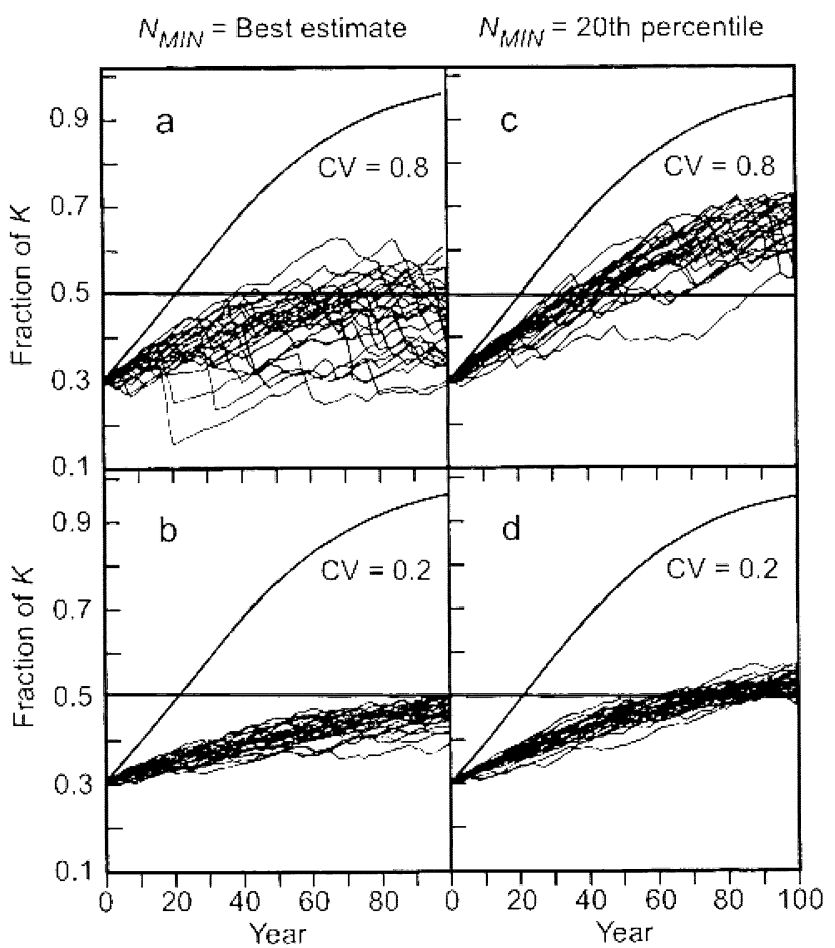

Figure 1. Thirty sample trajectories of populations recovering from a depleted level of $0.3 \mathrm{~K}$. In each case, the sigmoidal curve shows the expected trajectory with no buman-caused mortalities, and the borizontal line at $0.5 \mathrm{~K}$ shows the management objective of the maximum net productivity level. All cases use equation 2 with $\mathrm{R}_{M A X}=$ 0.04 (cetaceans) and $\mathrm{F}_{\mathrm{R}}=1.0$ (no biases). Parts $a$ and $b$ assume $\mathrm{N}_{M I N}$ is the mean (best) abundance estimate (assuming the estimates are log-normally distributed). Parts $c$ and $d$ use the lower twentieth percentile of the abundance distribution as $\mathrm{N}_{M I N}$. 
estimation, fisheries removal, and population growth for a range of plausible scenarios. For example, dolphin populations typically have a maximum growth rate of $4 \%$ per year and abundance estimates with coefficients of variation around 0.2. Sample trajectories for simulations vary (Fig. 1) because sometimes abundance is over- or underestimated, resulting in allowed kills that vary accordingly. Different percentages of the abundance estimate $\left(N_{\text {MIN }}\right)$ are used, and the performance is measured by the proportion of time the population is $\geq$ MNPL after 100 years. The percentage used for $N_{\mathrm{MIN}}$ is the one that results in the objective being met $95 \%$ of the time, which occurred at the lower twentieth percentile (Figs. 1c \& 1d).

The simulations clearly show that accounting for uncertainty by using a lower percentile is precautionary, whereas the typical practice of the best estimate is not (Fig. 1). Figures $1 \mathrm{a}$ and $1 \mathrm{~b}$ use the "best" abundance estimate for $N_{\text {MIN }}$ in equation 2, and Figs. 1c and 1d use the lower twentieth percentile of the abundance estimate distribution for $N_{\text {MIN }}$. Using the "best" estimate manages less well-known populations (with lower precision abundance estimates) less conservatively (contrast Figs. 1a \& 1b; see also Taylor 1993). Using a lower percentile of the abundance, in contrast, manages less well-known populations more conservatively (Figs. 1c \& 1d). The reason that populations in Fig. 1c achieve on average a higher abundance than those in Fig. 1d is because the allowed kill is smaller. A fishery wishing to improve this situation may well request that more precise data are gathered. Thus, simply incorporating the uncertainty related to the precision of the abundance estimate met two management goals: increasing the margin of safety commensurate with the level of our ignorance of the population and providing an incentive to gather more precise data.

The second step in tuning the model is to address uncertainty caused by bias. Returning to the marksman analogy, bias would be indicated if shots aimed at a target consistently missed in one direction. If the sights are improperly adjusted, the marksman may aim above the line but consistently hit below it. The correction is to tune the sights.

We addressed this uncertainty using a second parameter, the recovery factor $\left(F_{R}\right)$. After tuning the model to account for imprecision, we ran a second set of simulations to tune for potential biases in the key parameters: abundance, human-caused mortality, and maximum growth rate. For example, one scenario considered was overestimating the abundance by a factor of two. Such an overestimate could come from the relatively unlikely event of animals being attracted to the survey vessel or, more likely, from animals being included in the abundance estimate which were really part of another population. As a simple example, consider an exploited population of 1000 animals living adjacent to an unexploited population of equal size. Because we often cannot see population boundaries in the marine realm, these populations are accidentally treated as a single management unit. The result is that a kill is allowed that is about twice as high as it should be. The possibility of such errors led to the setting of default values for $F_{R}$ such that $95 \%$ of the simulated populations equilibrated within OSP despite such errors. If the possible factors that cause bias are eliminated, this parameter could be raised to a value of one, but, doing so would dramatically reduce the safety margin for managing the species (Taylor 1997).

The final parameter in equation 2 is $R_{\mathrm{MAX}}$. Using data from recovering populations, conservative default values were chosen when data were lacking or uncertain: 0.04 for whales and dolphins and 0.12 for seals and sea lions. Of course, data from the species or population of concern are used whenever available. Details of the simulations and rationale for default values are given by Wade (1998).

The result of including estimates of precision in calculating the PBR is that the expected equilibration level increases as the $\mathrm{CV}$ of the abundance estimate increases (the precision decreases) (Fig. 2), which is necessary to ensure meeting management goals with less precise data. The point where the PBR lines intersect the net productivity curve is the level at which the population is expected to equilibrate.

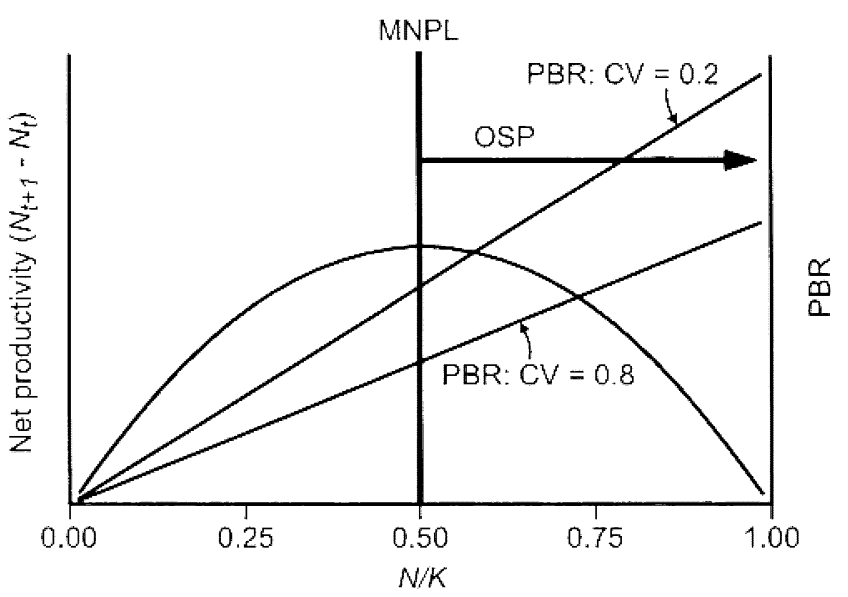

Figure 2. Net productivity and potential biological removal (PBR) for different levels of abundance/carrying capacity (N/K) with the same scale. Populations would be expected to equilibrate at the intersection point between the lines for PBR and the net productivity curve. These PBRs do not include the safety factor $\left(\mathrm{F}_{\mathrm{R}}\right)$, which would reduce PBRs to half for threatened or depleted stocks or stocks with unknown population structure or to one-tenth for endangered species. Maximum net productivity level (MNPL) is assumed to be at $0.5 \mathrm{~K}$ (vertical line). The objective is to keep populations above MNPL, which would then be called optimum sustainable populations (OSP) (borizontal arrow). 
We have addressed treatment of scientific uncertainties, but in management the uncertainty in the implementation of a management scheme cannot be overlooked. The PBR management scheme flags populations that may be experiencing unsustainable mortality and gives a target level of acceptable mortality. The PBRs are calculated for each stock by federal government scientists and are presented in stock assessment reports. These reports are reviewed by three regional "scientific review groups," bodies of nonfederal scientists representing perspectives of state agencies, academia, fisheries, and environmental groups, who make recommendations on research priorities and the adequacy of the data used. Stocks for which estimated fishery-caused mortality exceeds PBR are termed strategic. Regulations are not automatically imposed on fisheries when kills exceed the PBR. Instead, data are scrutinized for the potential that biases can be reduced by improving abundance estimates or stock definitions. Several species originally listed as strategic have been removed from the list as dedicated research was conducted to correct for suspected biases. If, however, the data are sound and fisheries contribute significantly to mortalities in strategic stocks, a "take reduction team" is formed. The team, composed of fishers, environmentalists, state and federal government representatives, and scientists, is charged with the task of recommending means to reduce the kills (take) to levels at or below PBR within 14 months subsequent to the finalization of the stock assessment reports.

\section{Results of Current Management Model}

After the first year of implementation (1994), stock assessment reports were written for 153 stocks in U.S. waters, and PBRs were published for 89 stocks (Barlow et al. 1995a; Blaylock et al. 1995; Small \& DeMaster 1995) (Table 2). For 22 additional stocks, PBRs were not published but either an approximate PBR level or a lack of evidence for any human-caused mortality allowed the stock to be classified, resulting in 112 out of 153 stocks (73\%) being assessed. Kills exceeded PBR for 24 stocks of marine mammals. Although some of these, such as harbor porpoise in the Gulf of Maine, were known to be at risk before the management scheme was instituted, many were species that had received no attention in the past. Chief among these were species of whales that spend long periods of time beneath the surface, including sperm whales (Pbyseter macrocephalus) and numerous beaked whales (Family Ziphiidae).

The stock assessment reports reveal both stocks that are at risk and gaps in what we need to know to manage properly. Comprehensive surveys off the Pacific and Atlantic coasts were completed in 1996 and 1998, respectively. Because the law mandates monitoring, surveys are planned to continue on a rotational schedule. Testing of the scheme has also made clear the importance of understanding population structure and genetic sampling, which are becoming an integral part of survey design. Knowing the spatial distribution of kills allows formulation of stock boundary hypotheses needed to interpret genetic data (Taylor \& Dizon 1996; Taylor 1997). Take reduction teams have been formed, and research is underway to develop techniques to reduce the number of marine mammals killed in fisheries to as near zero as is practicable.

\section{Comparisons between the Models}

The fundamental problem when management involves potentially limiting human-caused mortality is determining the acceptable level of kill. The old model attempted to do this by determining the status of the population relative to $K$. The model failed as a management technique and provided little improvement in our scientific understanding of marine mammal biology. Recognizing our inability to estimate MNPL for most species, we turned to using trends in abundance as an indicator of population health. Using trends has two important limitations. First, the burden of proof is nearly always to prove that the population is declining (Thompson et al., this issue). Low precision in abundance estimates makes such proof so difficult that management actions cannot take place before populations become severely depleted. Although

Table 2. Summary of the number of marine mammal stocks by region that were assessed in 1995 by the National Marine Fisheries Services under the potential biological removal (PBR) management scheme.

\begin{tabular}{lcccccc}
\hline Region & Stocks & $\begin{array}{c}\text { PBR and } \\
\text { mortality }^{a}\end{array}$ & $\begin{array}{c}\sim \text { PBR and } \\
\text { mortality }^{b}\end{array}$ & $\begin{array}{c}\text { No PBR but } \\
\text { no mortality }^{c}\end{array}$ & $\begin{array}{c}\text { Total } \\
\text { assessed }^{d}\end{array}$ & \multicolumn{1}{c}{ Source } \\
\hline Alaska & 35 & 20 & 0 & 7 & 27 & Small \& DeMaster 1995; NMFS 1995 \\
Atlantic & 62 & 40 & 8 & 5 & 53 & Blaylock et al. 1995; NMFS 1995 \\
Pacific & 56 & 29 & 1 & 2 & 32 & Barlow et al. 1995a; NMFS 1995 \\
Total & 153 & 89 & 9 & 14 & 112 &
\end{tabular}

${ }^{a}$ Number of stocks for which PBR and total human-caused mortality were calculated.

${ }^{b}$ Number of stocks for which PBR was not calculated but for which an approximate PBR level was available along with a calculation of total buman-caused mortality.

${ }^{c}$ Number of stocks for which no PBR was calculated but for which there was no known human-caused mortality.

${ }^{d}$ Sum of the previous three categories. 
there is the potential of either shifting the burden of proof or reducing the level of proof needed to show a decline (raising the $\alpha$ level), there is still the problem of interpreting the cause of the decline and whether the decline is acceptable or not. Consider, for example, a demonstrated decline of $40 \%$. Even if a $40 \%$ decline was considered acceptable, as it would be under the PBR scheme, biologists would still need to determine whether the decline was likely to continue and what part of that decline, if any, was a result of human-caused mortality.

The PBR approach is much more direct because it monitors the factor (human-caused mortality) that may need management. Rather than waiting until a population has been depleted to begin taking action, the PBR approach starts reducing mortality when it is apparent that current kill levels will lead to depletion. Yet the approach does require an estimate of kill, which is not an easy task. Estimating human-caused mortality is likely to be difficult for both marine and terrestrial species. Gathering data is likely to be costly if the mortalities are a result of low impact by many people. In our case, estimates are especially poor for fisheries with large numbers of small boats, often operated by one person. Assuring adequate coverage would require a much higher level of funding than is currently allocated to this problem. Insufficient funding is connected to the second general problem: obtaining funding for scrutiny of private enterprise is not politically popular. Although the estimation procedure is difficult, it is unwise to rely on reports from the resource users, and it is clear that management cannot succeed without some estimate of the number of animals being killed. Some creative thinking about how to estimate human kills is desperately needed to understand the magnitude of human impact on wild populations.

The definition of management units has stymied both past and current management. Understanding population structure is fundamental to any management scheme but remains at or beyond our scientific limits. The International Whaling Commission uses a precautionary approach by defining "small areas." These areas are created to be so small that biologists believe it is not possible to have more than one population in that area. Although this approach is precautionary and requires only rudimentary knowledge of the populations, it is also controversial because no standard exists to determine when evidence is sufficient to justify increasing the size of small areas.

The original PBR guidelines (Barlow et al. 1995b; Wade \& Angliss 1997) essentially tried to make initial management units equivalent to small areas. Scientists from different regions, however, did not agree with this definition and created their own definitions. Some felt it beyond their prerogative as scientists to draw lines on a map when data were few to nonexistent. But refusing to draw boundaries does not leave the management as "undefined" with no kills allowed but rather defines the management unit as the range of the species and puts the burden on scientists to prove that population structure exists before any management actions will be taken.

The success of this management scheme depends in large part on proper definition of stocks or use of $F_{R}$ to account for potential biases. If stocks are defined in large units, such as the entire Pacific coast, it is likely that localized fisheries will never exceed PBR; therefore, any management actions needed to preserve the integrity of the range would not occur. Obtaining measures of population structure for marine mammals is difficult because their aquatic nature limits access for research. Requiring proof of structure means at least lengthy delays until management units are adequately defined. Indeed, requiring such proof may make the new management scheme as ineffective as the old scheme for some species, because a required parameter is essentially impossible to estimate.

\section{Discussion}

The history of marine mammal management clearly demonstrates the need to incorporate uncertainty into management models. Simple biological models, which did not incorporate uncertainty, resulted in inaction or failed management. The model now used to manage marine mammal populations in the United States is simple enough for both the regulators and the regulated to understand, it relies on parameters that can be estimated, and it rewards the reduction in uncertainty with less conservative management while allowing management actions despite uncertainty. By mandating monitoring of both abundance and human-caused mortality, we have already greatly increased our general knowledge of marine mammal populations and identified unsuspected atrisk species and stocks that otherwise would have been missed.

One of the most positive aspects of the new management scheme is separating science from policy through the use of performance criteria. Parties on either side of management decisions may disagree with the criteria. For example, some may want populations to remain at higher levels, whereas others may be satisfied with a higher chance of not meeting management objectives. Neither party, however, is likely to disagree with the estimated level of precision of abundance estimates or use this uncertainty as a rationale for not taking action until uncertainty is removed.

One of the most argued parts of the model is the default used for $F_{R}$. This default was set at 0.5 to account for unknown biases based on the results of simulation trials. It is difficult to set a value objectively for an unknown bias. Although quite a large bias (e.g., only onehalf of the kills reported or the abundance estimated as 
twice the true abundance) would be needed before any single factor resulted in failure to meet management objectives, rather small biases in several factors would lead to the need for $F_{R}=0.5$ to meet management objectives. It is possible to raise $F_{R}$ by presenting evidence that biases in abundance, stock structure, growth rate, and kills are unlikely or very small. Setting $F_{R}=1.0$ allows no room for bias in any of these factors.

The simplicity of the management model may trouble ecologists who are used to models of ecosystems. The number of parameters needing estimation for an ecosystem model make such models unlikely to be useful as direct management tools. Indeed, the first 20 years of management under the MMPA failed because of the inability to estimate parameters for a fairly simple model. Although the marine mammal management model is simple, it seems to gather the baseline data for all species and affect management of some fisheries interaction problems. There are also marine mammal populations experiencing declines that cannot be explained by incidental fisheries kills, such as the ongoing decline of Steller sea lions (Eumatopias jubatus). More complex biological models will continue to help us understand the causes for these declines and may eventually result in modifications to the management model to address such factors as reduced growth rate caused by competition for fish with humans. In the meantime, we have a working management scheme that addresses one major risk factor for marine mammals: direct human-caused mortality.

Many other terrestrial and marine species are also at risk from direct human-caused mortality. For such species, a simple management model such as the PBR scheme, may allow adequate management despite many uncertainties about a particular species. At a minimum, managers must have estimates of abundance (and its precision) and of human-caused mortality. It is important for managers to realize that successful management of human-caused mortality must be based on these data at a minimum. It is remarkable how few long-term programs are in place to monitor abundance, yet it is difficult to imagine a more essential piece of information for good management. It is also important for research to be dedicated to estimating human-caused mortality because history has clearly demonstrated the inadequacy of relying on reports generated by the potentially affected resource users. Carefully chosen defaults can be used for parameters concerning maximum population growth rate and population structure. The PBR scheme required setting quantitative management objectives and has yielded a clear measure of performance: PBR versus the estimated kill. Reducing human-caused mortality to levels below PBR also gives the concerned parties a clear goal around which to organize both further research and conservation actions.

Indirect and direct human-caused mortality pose the greatest risks to marine species, and we have directed our management efforts accordingly. Habitat loss may pose greater risks for the management of terrestrial species. Although the problems may differ, the following general lessons from our marine experience apply: (1) models must be based on parameters that are easily estimated; (2) uncertainty should be directly incorporated not only so management can proceed despite uncertainty but so that management is more conservative the greater the uncertainty; and (3) management objectives should be quantitatively defined as performance criteria to both separate science from policy and allow the management models to be tuned by means of simulations.

\section{Acknowledgments}

We thank our many colleagues in the National Marine Fisheries Service for the years of experience studying marine mammals that led to the realization of the knowledge we are likely to gain in our scientific lifetimes. Thanks to S. Reilly, E. Edwards, K. Ralls, and two anonymous reviewers. Our salaries were paid by the National Marine Fisheries Service and the Office of Protected Resources within that agency.

\section{Literature Cited}

Barlow, J., and P. Boveng. 1991. Modelling age-specific mortality for marine mammal populations. Marine Mammal Science 7:84-119.

Barlow, J., R. L. Brownell Jr., D. P. DeMaster, K. A. Forney, M. S. Lowry, S. Osmek, T. J. Ragen, R. R. Reeves, and R. J. Small. 1995a. U.S. Pacific marine mammal stock assessments. NOAA technical memorandum NOAA-TM-NMFS-SWFSC-219. Southwest Fisheries Science Center, La Jolla, California.

Barlow, J., S. Swartz, T. Eagle, and P. R. Wade. 1995b. U.S. marine mammal stock assessments: guidelines for preparation, background, and a summary of the 1995 assessments. NOAA technical memorandum NOAA-TM-NMFS-OPR-6. National Marine Fisheries Service, Silver Spring, Maryland.

Barlow, J., and D. Hanan. 1995. An assessment of the status of harbor porpoise in central California. Report of the International Whaling Commission, Special Issue 16:123-140.

Blaylock, R. A., J. W. Hain, L. J. Hansen, D. L. Palka, and G. T. Waring. 1995. U.S. Atlantic and Gulf of Mexico marine mammal stock assessments. NOAA technical memorandum NMFS-SEFSC-363. National Marine Fisheries Service, Southeast Fisheries Science Center, Miami.

Boveng, P. 1988a. Status of the Pacific harbor seal population on the U.S. west coast. Administration report LJ-88-06. Southwest Fisheries Science Center, La Jolla, California.

Boveng, P. 1988b. Status of the California sea lion population on the U.S. west coast. Administration report LJ-88-07. Southwest Fisheries Science Center, La Jolla, California.

Boveng, P. 1988c. Status of the northern elephant seal population on the U.S. west coast. Administration report LJ-88-05. Southwest Fisheries Science Center, La Jolla, California.

Boveng, P., D. P. DeMaster, and B. S. Stewart. 1988. Dynamic response analysis. III. A consistency filter and application to four northern elephant seal colonies. Marine Mammal Science 4:210-222.

Breiwick, J. M., E. D. Mitchell, and D. G. Chapman. 1981. Estimated initial population size of the Bering Sea stock of bowhead whale, Bal- 
aena mysticetus: an iterative method. Fishery Bulletin, United States 78:843-853.

Cooke, J. G. 1994. The management of whaling. Aquatic Mammology 20:129-135.

Fowler, C. W. 1984. Density dependence in cetacean populations. In W. F. Perrin, R. L. Brownell Jr., and D. P. DeMaster, editors. Reproduction in whales, dolphins, and porpoises. Report of the International Whaling Commission, Special Issue 6:401-441.

Fowler, C. W. 1988. Population dynamics as related to rate of increase per generation. Evolutionary Ecology 2:197-204.

Gehringer, J. 1976. Part 216: regulations governing the taking and importing of marine mammals. Federal Register 41:55536.

Gerrodette, T., and D. P. DeMaster. 1990. Quantitative determination of optimum sustainable population level. Marine Mammal Science 6:1-16

Gilpin, M. E., T. J. Case, and F. J. Ayala. 1976. $\theta$-selection. Mathematical Biosciences 32:131-139.

Goodman, D. 1981. Life history analysis of large mammals. Pages 415436 in C. W. Fowler and T. G. Smith, editors. Dynamics of large mammal populations. Wiley, New York.

Goodman, D. 1988. Dynamic response analysis. I. Qualitative estimation of stock status relative to maximum net productivity level from observed dynamics. Marine Mammal Science 4:183-195.

Hobbs, R. C., and L. L. Jones. 1993. Impacts of high seas driftnet fisheries on marine mammal populations in the North Pacific. Bulletin of the North Pacific Commission 53:409-434.

Holt, R. S., and J. E. Powers. 1982. Abundance estimation of dolphin stocks in the eastern tropical Pacific yellowfin tuna fishery determined from aerial and ship surveys to 1979. NOAA technical memorandum-23. National Marine Fisheries Service, Southwest Fisheries Center, La Jolla, California.

Holt, S. J., and L. M. Talbot. 1978. New principles for the conservation of wild living resources. Wildlife Monographs 59.

Joseph, J. 1994. The tuna-dolphin controversy in the eastern Pacific Ocean: biological, economic, and political impacts. Ocean Development and International Law 25:1-30.

Lo, N. C. H., and T. D. Smith. 1986. Incidental mortality of dolphins in the eastern tropical Pacific, 1959-72. Fishery Bulletin, United States 84:27-33.

Marine Mammal Commission. 1982. Marine Mammal Commission annual report to Congress. Bethesda, Maryland.

Marine Mammal Protection Act of 1972. (16 United States Code 13611407, Pub. L. 92-522, 86 Stat. 1072, Oct. 21, 1972).

Merrick, R. L., T. R. Loughlin, and D. G. Calkins. 1987. Decline in abundance of the northern sea lion, Eumotopias jubatus, in Alaska, 1956-86. Fishery Bulletin, United States 85:351-365.

Moritz, C. 1994. Defining 'evolutionary significant units' for conservation. Trends in Ecology and Evolution 9:373-375.

National Marine Fisheries Service. 1995. Notice of completion of final marine mammal stock assessment reports and guidelines. Federal Register 60:44308.

Pella, J. J., and P. K. Tomlinson. 1969. A generalized stock production model. Bulletin of the Inter-American Tropical Tuna Commission 13:420-496.

Perrin, W. F. 1969. Using porpoise to catch tuna. World Fishing 18:42-45.

Ragen, T. J. 1990. The estimation of theoretical population levels for natural populations. Ph.D. thesis. University of California, San Diego.

Reilly, S. B. 1981. Population assessment and population dynamics of the California gray whale (Eschrichtius robustus). Ph.D. thesis. University of Washington, Seattle.
Reilly, S. B. 1992. Population biology and status of eastern Pacific gray whales: recent developments. Pages $1062-1072$ in D. R. McCullough and R. H. Barrett, editors. Wildlife 2001: populations. Elsevier Science, Essex, United Kingdom.

Scott, G. P., D. M. Burn, and L. J. Hansen. 1988. The dolphin dieoff: long term effects and recovery of the population. Pages 819-823 in Ocean's 88: proceedings. Volume 3. Catalog no. 88-CH2585-8. Institute of Electrical and Electronics Engineers, New York.

Small, R. J., and D. P. DeMaster. 1995. Alaska marine mammal stock assessments 1995. NOAA technical memorandum NMFS-AFSC-57. Alaska Fisheries Science Center, Seattle.

Smith, T., editor. 1979. Report of the status of porpoise stocks workshop (August 27-31, 1979, La Jolla, CA). Administrative report LJ-79-41. Southwest Fisheries Science Center, La Jolla, California.

Smith, T. 1983. Changes in size of three dolphin (Stenella spp.) populations in the eastern tropical Pacific. Fishery Bulletin, United States 81:1-13

Smith, T. D. 1984. Estimating the dolphin population size yielding maximum net production. Report of the International Whaling Commission. Special Issue 6:187-190.

Taylor, B. L. 1993. "Best" abundance estimates and best management: why they are not the same. NOAA technical memorandum. NOAA TM-NMFS-SWFSC-188. Southwest Fisheries Science Center, La Jolla, California.

Taylor, B. L. 1997. Defining "population" to meet management objectives for marine mammals. Pages 347-364 in A. E. Dizon, S. J. Chivers, and W. F. Perrin, editors. Molecular genetics of marine mammals. Special publication 3. Allen Press, Lawrence, Kansas.

Taylor, B. L., and D. P. DeMaster. 1993. Implications of non-linear density dependence. Marine Mammal Science 9:360-371.

Taylor, B. L., and A. E. Dizon. 1996. The need to estimate power to link genetics and demography for conservation. Conservation Biology 10:661-664.

Taylor, B. L., and T. Gerrodette. 1993. The uses of statistical power in conservation biology: the vaquita and Northern Spotted Owl. Conservation Biology 7:489-500.

Wade, P. R. 1993a. Estimation of historical population size of the eastern spinner dolphin (Stenella longirostris orientalis). Fishery Bulletin, United States 91:775-787.

Wade, P. R. 1993b. Estimation of historical population size of the northeastern stock of offshore spotted dolphin (Stenella attenu$a t a)$. Administrative report LJ-93-18. Southwest Fisheries Science Center, La Jolla, California.

Wade, P. R. 1994. Abundance and population dynamics of two eastern Pacific dolphins, Stenella attenuata and Stenella longirostris orientalis. Ph.D. dissertation. Scripps Institution of Oceanography, University of California, San Diego.

Wade, P. R. 1998. Calculating limits to the human-caused mortality of cetaceans and pinnipeds. Marine Mammal Science 14:1-37.

Wade, P., and R. Angliss. 1997. Guidelines for assessing marine mammal stocks: report of the GAMMS Workshop. NOAA technical memorandum NMFS-OPR-12. National Marine Fisheries Service, Silver Spring, Maryland.

York, A. E. 1987. Northern fur seal, Callorbinus ursinus, eastern Pacific population (Pribilof Islands, Alaska, and San Miguel, California). Pages 9-21 in J. P. Croxall and R. L. Gentry, editors. Status, biology and ecology of fur seals. NOAA technical report NMFS 51. National Oceanic and Atmospheric Administration, U.S. Department of Commerce, Seattle.

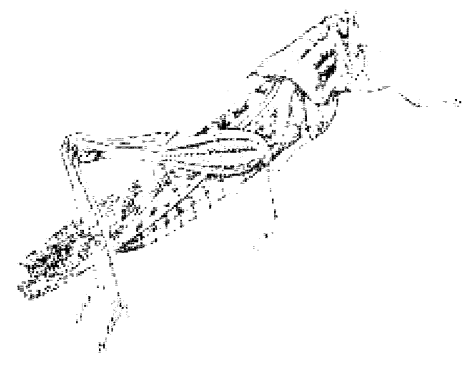

